\title{
Women And Wedlock: A Study On Female Marital Status Among the Hindus, Muslims and Christians of Assam, India
}

\author{
Keemee Das $^{+*}$ and Dr Madhushree Das ${ }^{\complement}$
}

\section{Abstract}

Although marriage is a social institution but marital status and age at marriage are important demographic determinants as these aspects influence the pattern of fertility and natural growth of population. Studying the various aspects of marital status of any population group especially the figures related to women can give an exposition about the probability of fertility rate as well as social manifestation prevailing in the society. It also helps to understand the preferred specific age at marriage for women. However, little is known about the marital status of women living in Assam cutting across religions-Hindu, Muslim and Christian. In this backdrop, an attempt has been made through this research to examine the changing trend of marital status among the Hindu, Muslim and Christian women of Assam. The research is based on secondary data and Census information and considers the entire state of Assam. Census data of 2001 and 2011 shows interesting and striking information about the changing situation of marital status among the Hindus, Muslims and Christians of the state. It is arguable that the study linked to female marital status is saliently more influencing in this context as it determines the socio-economic status of women and pattern of fertility in any society. Among the different religions of Assam, Hindu women have the highest married proportion followed by Christian while Muslim is the lowest in the same category. Depending on the socio-cultural practices, economic conditions and the level of educational attainment, the age at marriage varies among the religious groups. The proportion of woman being married at a younger age has been less, is an indication of advancement in the educational scenario.

Keywords: Marital Status, Age at Marriage, Demographic Determinant, Population, Census, Assam, India

\footnotetext{
${ }^{\dagger}$ Research Scholar, Department of Geography, Gauhati University, Guwahati, Email:keemee.only1@gmail.com

${ }^{*}$ Corresponding Author

IProfessor, Department of Geography, Gauhati University, Guwahati, Email: madhushreedas@yahoo.com C2018 Das and Das. This is an Open Access article distributed under the terms of the Creative Commons Attribution License (http://creativecommons.org/licenses/by/2.0), which permits unrestricted use, distribution, and reproduction in any medium, provided the original work is properly cited.
} 


\section{Introduction}

It is well established that in India, marriage is a social institution, which plays an important role in the manifestation of the socio-cultural and demographic scenario of the country. However, few aspects related to marriage such as the marital status and age at marriage are important demographic determinants as these aspects influence the pattern of fertility and natural growth of the population. "Marital status is an indicator to know the demographic character and also social well-being of population in any region. Marital status of a population includes never-married population, married population, widow or widower population and divorced or separated population in respect of males and females" (Das, 2012: pp 42-43). Studying the various aspects of marital status of any population group especially the figures related to women can give an exposition about the probability of fertility rate as well as social manifestation prevailing in the society. It also helps to understand the preferred specific age at marriage for women. Moreover, 'age at marriage' is also considered as a vital demographic determinant as it is linked with the fecundity period as well as socio-economic status of a woman. According to the Child Marriage Restriction Act of 1978, the legally prescribed minimum age at marriage in India is 18 years for girls and 21 years for boys (Das, 2012). Getting married at an age below the legal age at marriage is also not permissible on medical and health basis. Thus, it can be stated that marital status of women and their age at marriage are important demographic determinants that shapes the structure and size of any population group within a region. Although, there is an emerging literature on varied dynamics of marriage of Indian women (such as status and development of married women, married women's decision making power, reproductive status and health, preference for son, etc.), far too little is known about marital status and age at marriage of women of Assam belonging to the three main religious groups (Hindus, Muslims and Christians). Hence, the present study has been undertaken to understand the various aspects of marital status of the Hindu, Muslim and Christian women of Assam.

The article begins with a brief review of literature relevant to the research. This follows a discussion of the methodological issues deployed in this research. The final section draws on the results and discussion.

\section{Literature Review}

The notion 'status of women' are multi-faceted and are defined by the scale of women's access to education, improved health, ingress to socioeconomic resources, political power and power to make decisions in personal and familial matters (Status of Woman and Family Planning, Department of Economic and Social Affairs, the United Nations, 1975; Bhattacharyya, 2009; 2013; Hoffman, 1977; Goldman et al., 1995; Gove, 1972; Waldron et al., 1996; William and Umberson, 2014; Umberson, 1992). The United Nations (UN) established the Commission on the Status of Women in 1946, a global intergovernmental body aimed at promoting gender equality and women's empowerment. On 10 December 1948, the UN General Assembly adopted the draft Universal Declaration of Human Rights which states:

All human beings are born free and equal in dignity and rights and that "everyone is entitled to all the rights and freedoms set forth in this Declaration, without distinction of any kind, such as race, colour, sex, language, religion, birth or other status. ${ }^{1}$

With the radicalisation of feminist movement during the 1970s (Bhattacharyya, 2009), the UN General Assembly adopted the International Bill of Rights for Women popularly known as Convention on the Elimination of All Forms of Discrimination against Women (CEDAW) in 1979. This Convention addressed that the key forces shaping gender roles and relations in

\footnotetext{
${ }^{1}$ The United Nations and Women, United Nations, retrieved 30 March 2018 from

http://www.un.org/en/sections/issues-depth/women/
} 
families are culture and tradition of a particular society. ${ }^{2}$

Following the 1993 UN General Assembly declaration on the Elimination of Violence against Women advocated women's rights as human rights and asserted that well defined actions must be taken ensuring protection and respect of those rights. ${ }^{3}$

From 12 to 23 March 2018, the 62nd session of the Commission on the Status of Women was held at the United Nations Headquarters in New York. Although, women's status from across the globe have improved to a certain level but many nations failed to attain the Millennium Development Goals by the end of 2015. From 1 January 2016, the UN's 17 Sustainable Development Goals (SDGs) of the 2030 Agenda for Sustainable Development has been in operation all over the globe with view to transform the world. ${ }^{4}$ Agarwal (2016) emphasised the need to clarify the material dimensions of power and gender biasedness existing in terms of command over property. Taking these observations into consideration, it is argued that inequalities with respect to all indicators of women's status continue to remain all over the place. The presence of domestic violence (DV) is a universal phenomenon and married women are exposed to such inequalities across the world wherein the incidences of Bangladesh were treated with great in depth study with an effort to co-relate socio-economic and cultural factors influencing the occurrence of the domestic violence within the country (Das et.al; 2015; 2016). In the said context, it can be argued that DV is rampant

\footnotetext{
2 Please refer to footnote 1

${ }^{3}$ Beijing Declaration and Platform for Action, The Fourth World Conference on Women, 4 to 15 September 1995, retrieved 20 March from, http://www.un.org/womenwatch/daw/beijing/pdf/BDPf A\%20E.pdf

${ }^{4}$ Sustainable Development Goals kick off with start of new year, United Nations, retrieved on 23 March 2018 from,

https://www.un.org/sustainabledevelopment/blog/2015 /12/sustainable-development-goals-kick-off-with-startof-new-year/
}

across India (Bhattacharyya, 2015) including the state of Assam (Vauquline, 2015).

The recent \#metoo movement that has rolled out to different geographical spaces of the world is another witness to the fact that even highly economic empowered women of Hollywood, Westminster and European Parliament have become victims of sexual assaults and continues to remain at risk of being assaulted (Bhattacharyya, 2018). This research, however, is to understand the various aspects of marital status of women of Assam belonging to three religions-Hindus, Muslims and Christians.

It is well established that the marital status of women and various aspects associated with it influences the status of women indifferent societies to a great extend (Bhattacharyya, 2009; Hoffman, 1977; Goldman et al., 1995; Gove, 1972; Sur, 2014; 2015; Waldron et al., 1996; William and Umberson, 2004; Umberson, 1992). Marital status of women also symbolises their position and responsibilities within a family as well as have an alternate effect on the professional life of women. It also imparts the patriarchal system existing in our societies (Bhattacharyya, 2009; 2015; 2016; Bhattacharyya and Singh, 2017) where women at different stages of their lives are believed to be dependent on male members of the family for shelter and security (Das, 2012; Kar, 2001; 2002). Marital status of women is not just regarded as social position of women in our societies but also treated as sex role orientation and role reversal of women (Bhattacharyya, 2009). Thus, to understand the social status of women in Assamese society, it is important to understand the marital status of women of Assam as various aspects like health and empowerment of women, their independence and security, demographic structure of the society as well as mind-set of people-is all associated with a woman "being married, unmarried, divorced or separated". A significant proportion of the women resolve this paradox by claiming their career and family occupy equal importance in their lives and by denying any real conflict between aspirations 
for a career and expectations of marriage and motherhood. This leads to the popular sense of striking a dignified compromise between domesticity and ambition (Bhattacharyya 2009). Moreover, age at marriage especially for women has also a great impact on the social conditions of any region or population group. Age at marriage of women not only determines the demographic shaping of any population within a given area but also has close associates with health conditions and economic status of women.

It can be easily argued that the practices of child marriage leads to ill health of women and girls; increases the cases of school dropouts among girl students; increases the reproductive span of women leading to the possibility of more number of pregnancy cases and children as a result of which the population size are affected (Bhattacharyya and Singh, 2017; Srivastava, 2018). In these regards, the research work of Havens (1973) have been highly appreciated for discussing the impact of marriage on self-development and economic status of women living in the United States nearly 45 years ago. Weingarten (1985) in his work have illustrated the relationships between marital status and well-being of both men and women in building a healthy society. Similarly, in the context of North East India, Kar (2001 and 2002) have elaborately dealt with the marital status of women and the changing pattern of marital composition among women of the region along with their attitude towards marriage. Das (2012) seemingly has discussed the various issues related to the marital status of tribal of Assam. However, in a slightly different context, Nizami and Ahmad (2005) outlined a detailed demonstration of the influence of marital status of women in their role reversal which affects the women power to a great extent. In familial context, Bhattacharyya (2009) have extensively discussed on the changing role of women in Assamese society and the challenges confronted by women to fulfil their higher education and employment opportunities.
Notwithstanding, one has to acknowledge that India continues to face the problem of child marriage (Bhattacharyya and Singh, 2017). According to the latest data of the United Nations Children's Agency, UNICEF, March 2018, the percentage of child marriage for the period 2010-2017 stands at 7 per cent (women married under 15 years) and 27 per cent (women married under 18 years). ${ }^{5}$ However, during the last decade, the number of child marriage in India has plummeted, "which has contributed significantly to a global decline in child marriage" (Srivastava, 2018). It declined from 47 per cent in 2006 to 27 per cent in 2016. ${ }^{6}$ The Prohibition of Child Marriage Act, 2006 penalises a fine of $₹ 100,000(\$ 1,535)$ in addition to two years in prison for parents, who tries to marry off children before they become legally eligible (the laws ${ }^{7}$ require, the females to be 18 years and the males to be 21 years for marriage). ${ }^{8}$ However, the problem of child marriage is entrenched deeply in societal values and is pervasive across the country (Bhattacharyya and Singh, 2017; Srivastava, 2018). Assam is no exception. State Fact Sheet, Assam, National Family Health Survey (NFHS)-4, 2015-2016 unveils that 30.8 per cent (24.3 per cent urban and 31.9 per cent rural) women aged between 20-24 were married before they attained 18 years, albeit this is a decline by 7.8 percentage points from NFHS-3 conducted in 2005-2006. ${ }^{9}$ Taking all these observations into context, this research aims to examine the

\footnotetext{
${ }^{5}$ Child marriage is a violation of human rights, but is all too common, UNICEF, retrieved 20 March 2018 from, https://data.unicef.org/topic/child-protection/childmarriage/

${ }^{6}$ Child Marriage, UNICEF India, retrieved 20 March 2018 from, http://unicef.in/Whatwedo/30/Child-Marriage ${ }^{7}$ After India's independence, The Child Marriage Restraint Act, 1929 was amended and renamed as The Child Marriage Restraint Act 1978. However, this act carried loopholes. In order to address these loopholes, The Prohibition of Child Marriage Act, 2006 was enacted. ${ }^{8}$ The Prohibition of Child Marriage Act, 2006, Act No. 6 of 2007, National Commission for Women, retrieved on 20 March 2018 from, http://ncw.nic.in/acts/pcma2006.pdf

${ }^{9}$ State Fact Sheet, Assam, National Family Health Survey4, 2015-2016,retrieved on 20 March 2018 from, http://rchiips.org/NFHS/pdf/NFHS4/AS_FactSheet.pdf
} 
change in trend (if any) in marital status among women belonging to Hindu, Muslim and Christian religious groups of Assam. In addition, this research aims to investigate the age at marriage for both male and female populace belonging to these religious groups. Interestingly, this research reveals that the percentage of married women among the Hindu, Muslim and Christian population groups have increased during 2011 compared to 2001. Moreover, the study clarifies that the percentage of Hindu married women are more than the Muslim and Christian married women. The study further reveals that the percentage of unmarried women has increased over the last 10 years among all the three religious groups selected for the study. Again, taking into account the legal age at marriage for females, it is astonishing to state that the percentage of girls getting married before attaining 18 years of age have increased in 2011 as compared to 2001 among all the three religious groups with Muslim girls hitting the chart (Table 2). Surprisingly, the percentage of females getting married before attaining the legal age of marriage is higher in the urban areas than the rural counterfoils among all the selected religious groups. The next section discusses about the database and methodology.

\section{Database and Methodology}

The main purpose of this section is to enunciate the procedure and techniques involved in studying the marital status and age at marriage among women belonging to Hindu, Muslim and Christian religious groups in Assam. The data necessary for the work have been collected from secondary sources based on data derived from Census of India. The research deals with the major religious groups living in the state of Assam. According to the Census of India (2011), these religious groups are Hindus (61.47 per cent), Muslims (34.22 per cent) and Christians (3.74 per cent). ${ }^{10}$ It is important to mention here that these three groups have been considered in the present research as they have more than 1 per cent of total population and there is marked variation in the religious composition throughout the entire state on a spatio-temporal basis. This variation is also true among women of various religious groups in Assam. Moreover, these three religious groups together account for 99.43 per cent of the total population of the state. The present research is based on quantitative pattern of work where data have been collected from secondary source (Census of India 2001; 2011) and analysed using statistical techniques in Microsoft Excel sheet. The following section describes the study area.

\section{Study Area}

The entire state of Assam (Figure 1) has been taken into consideration in the present study to have an overall understanding of various aspects related to marital status among women of the selected religious groups. Among the different states of India, Assam, located in the north-eastern region of the country, $\left(24^{\circ} 8^{\prime}\right.$ $28^{\circ} 2^{\prime} \mathrm{N}$ and $89^{\circ} 42^{\prime}-96^{\circ} \mathrm{E}$ ) with a population size of 3116927 person (Census of India, 2011) represents the country's religious diversity. The state with a diverse population symphony and peopling process have paraded various types of religious groups along with a wealthy account of ethnic, linguistic faction of inhabitants (Das, 2012; Kar 2001; 2002).

\section{Results and Discussion}

Marriage is a social construct and is closely associated with religious as well as regional norms that exist within a population group in any area. Sociological attention often focuses on marriage as both cause and effect of diverse phenomena (Havens, 1973). Therefore, the statistics related to marital status of women should be analysed in a rational manner as this not only shapes the societal structure but also indicates women's well-being. It is associated with both demographic and social quality of human population in any region (Das, 2012; Kar, 2002).

\footnotetext{
${ }^{10}$ The percentage of the religious groups is shown in the parentheses.
} 


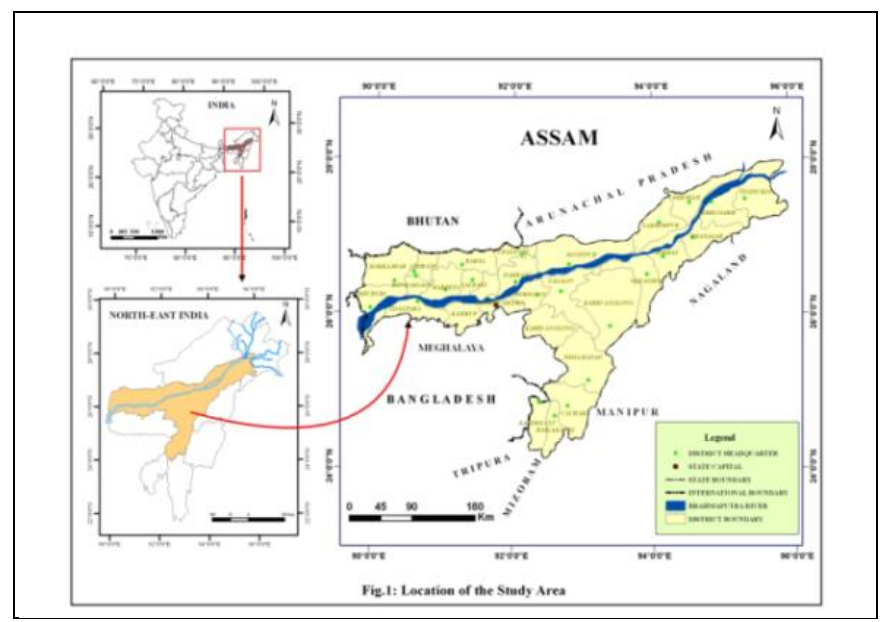

Figure 1: Location Map of Assam

The data retrieved from the Census of India (2001 and 2011) unravels interesting and striking information about the changing situation of marital status among the Hindus, Muslims and Christians of Assam (Table 1). Attention calls to be drawn on statistics that suggest a decline in the proportion of never married population (both male and female) in the recent years. Surprisingly, 2011 Census of India data reveals an increase in the proportion of divorced female ( 0.58 per cent) as compared to the 2001 census ( 0.53 per cent).Among the different religious groups of Assam as per 2001 and 2011 Census data, the proportion of married Hindu women is found to be highest (42.46 per cent and 47.15 per cent) followed by Muslims (40.55 per cent and 43.44 per cent) while Christians (39.08 per cent and 41.97 per cent) have the least percentage of married women. . This is completely reverse when never married female population is considered. The high percentage of Hindu girls under currently married category indicates the prevailing social custom which asserts marriage as a mandatory custom for a girl. More interesting is to note that Muslim have less proportion of married women compared to the Hindus of Assam. However, it must be noted that less proportion of married women and high birth rate among the Muslims is an indication of each married couple having more number of offspring. This is mainly because of early age at marriage among the Muslim women of Assam (Table 3 and Table 4). Such practices lead to natural rapid growth of population, due to lack of adaptation of birth control measures and social taboos associated with childbirth. Hindus and Christians with more married women and less fertility rate owes appreciation as it helps in balancing the growth rate of population. It also improves health condition of women and children leading to a more prosperous life style. These findings bear resonance to the previous studies (Gove, 1972; Waldron et al., 1996; Williams and Umberson, 2004; Umberson, 1992).

However, Hindus have a high percentage of widowed females (8.25 per cent) when compared to the Muslims (6.52 per cent)) and Christians (6.17 per cent). Significantly, divorced females are more in the Muslim community ( 0.86 per cent) followed by Hindus (0.44 per cent) and least in case of Christian women ( 0.42 per cent). In addition to this, the rural urban differential reflects similar trend in the marital status of women among these religious groups both for India, 2001 and 2011 Census, (Table 1). However, in the urban areas with Muslims women registers highest percentage of divorced or separated females (0.92 per cent) followed by Christian women (0.55 per cent) and Hindu women (0.49 per cent). Interestingly, the percentage of never married women is less in the urban areas compared to their rural counterparts among the Hindus (40.32 per cent in urban areas and 45.01 per cent in rural areas) and the Muslims (45.28 per cent in urban areas and 49.50 per cent in rural areas). On the contrary, Christians have more unmarried women in the urban areas (52.07 per cent) compared to rural counterfoils (51.41 per cent). Widowed females 
are more in the urban areas among Hindu and Muslim population while Christians have more share of rural females who are sufferers of widowhood. It is strikingly evident that the percentage of female divorcee is more in the urban areas among all the religious groups of the state.

Moreover, while comparing the parameters of marital status such as proportion of unmarried, currently married widow/widower and divorced or separated population both for male and female among the three religious groups, similar propensity is seen for both the census years of 2001 and 2011. The never married proportion of male are higher compared to the female share for the state as whole as well as for all the selected religious groups. Meanwhile married, widowed and divorced or separated women are more in share compared to male section of the state and among Hindu, Muslim and Christians in particular.

The considerable proportion of unmarried females indicates growing self-sufficiency among the women folk as a result of educational and occupational enhancement. This result echoes the findings as demonstrated by Bhattacharyya (2009; 2013). Besides, this observation also suggests relative acceptability of the society towards unmarried independent women. The percentage of separated or divorced couple has increased over the decade which is not a positive social and demographic indicator. This is much due to growing intolerance and the essence of self sufficiency among the individuals failing to built up a healthy marriage. More so to add in this matter is the highest share of divorced females among the Muslims when compared to other religions of Assam is associated with the religious custom which gives liberty to Muslim male (husband) of easy divorce system that prevails \{please refer to Sur, 2014; 2015; also Sur, 2018 on the Triple Talaq (divorce) Bill introduced in the Lok Sabha, House of the People of Indian Parliament in December 2017\}. In addition to this, the high percentage of widow compared to the widower among all the selected religious groups of Assam and most significantly in the urban areas asserts the high rate of life expectancy among the female folk and child marriage.

Marital status has close connotation with age at marriage. Age at marriage of women determines their reproductive span and probability of child bearing, thus, shaping the demographic structure of a population group. Age at marriage is therefore, a vital demographic determinant as it is linked with the fecundity period as well as socio-economic status of a woman. According to The Child Marriage Restriction Act of 1978 and The Prohibition of Child Marriage Act, 2006, the legally prescribed minimum age at marriage in India is 18 years for girls and 21 years for boys (Das, 2012). Getting married at an age below the legal age at marriage is also not permissible on medical and health basis. While investigating the percentage of females getting married at age below 18 years, it is discouraging and a matter of concern to divulge the statistics that suggest an increase in the rate of females under aged marriage in the state has raised from 1.77 per cent in 2001 to 2.09 per cent in 2011. In addition to this, although girls Hindu, Muslim and Christian communities are shown getting married before attaining the prescribed age at marriage, this is worst in the case of Muslim girls. This can be due to the prevailing practice of early age at marriage among the Muslims. There is a widespread belief that late age at marriage lowers the fertility period of women. This is also a reason for high percentage of unmarried female among the Muslims compared to the other religions. However it is astonishing that the percentage of marriage below the legal age is high in the urban areas compared to the rural correspondence in case of Assam and also for Hindu, Muslim and Christian of Assam (Table 2). Rural-urban migration at a tender age and low sex ratio in the urban areas are some of the reasons that obviously forces early marriage amongst females. Study reveals that males have outnumbered the female population size in most regions or community. 
Table 1: Marital Status among Hindus, Muslims and Christians of Assam, 2001-2011 (in percentage)

\begin{tabular}{|c|c|c|c|c|c|c|c|c|c|c|c|c|c|c|c|c|c|}
\hline \multirow{3}{*}{ Religious Groups } & \multirow[b]{3}{*}{ Area } & \multicolumn{4}{|c|}{ Never Married } & \multicolumn{4}{|c|}{ Currently married } & \multicolumn{4}{|c|}{ Widow/Widower } & \multicolumn{4}{|c|}{ Divorced/ Separated } \\
\hline & & \multicolumn{2}{|c|}{2001} & \multicolumn{2}{|c|}{2011} & \multicolumn{2}{|c|}{2001} & \multicolumn{2}{|c|}{2011} & \multicolumn{2}{|c|}{2001} & \multicolumn{2}{|c|}{2011} & \multicolumn{2}{|c|}{2001} & \multicolumn{2}{|c|}{2011} \\
\hline & & $\frac{0}{\sum^{\pi}}$ & 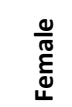 & $\frac{\frac{0}{\pi}}{\sum}$ & $\frac{\mathscr{0}}{\stackrel{\frac{0}{\pi}}{\varepsilon}}$ & $\frac{0}{\frac{0}{\pi}}$ & 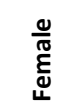 & $\frac{\frac{0}{\pi}}{\sum}$ & 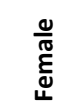 & $\frac{\frac{0}{\pi}}{\sum^{\pi / 2}}$ & 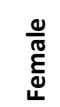 & $\frac{\frac{0}{\pi}}{\sum}$ & 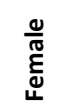 & $\frac{0}{\sum^{\pi}}$ & 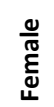 & $\frac{\frac{0}{\pi}}{\sum}$ & 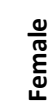 \\
\hline \multirow{3}{*}{ Hindus } & Total & 58.26 & 50.09 & 53.04 & 44.16 & 39.71 & 42.46 & 44.67 & 47.15 & 1.86 & 7.05 & 2.07 & 8.25 & 0.17 & 0.4 & 0.22 & 0.44 \\
\hline & Rural & 59.06 & 50.78 & 53.71 & 45.01 & 38.77 & 41.78 & 43.86 & 46.48 & 2.02 & 7.03 & 2.23 & 8.08 & 0.17 & 0.41 & 0.20 & 0.43 \\
\hline & Urban & 54.47 & 46.37 & 50.04 & 40.32 & 44.28 & 46.12 & 48.28 & 50.17 & 1.07 & 7.16 & 1.37 & 9.02 & 0.18 & 0.35 & 0.31 & 0.49 \\
\hline \multirow{3}{*}{ Muslims } & Total & 62.72 & 52.3 & 59.25 & 49.18 & 36.57 & 40.55 & 39.97 & 43.44 & 0.58 & 6.33 & 0.64 & 6.52 & 0.13 & 0.82 & 0.14 & 0.86 \\
\hline & Rural & 62.99 & 52.45 & 59.57 & 49.50 & 36.32 & 40.41 & 39.68 & 43.19 & 0.57 & 6.32 & 0.62 & 6.45 & 0.12 & 0.82 & 0.13 & 0.86 \\
\hline & Urban & 58.89 & 50.1 & 55.29 & 45.28 & 40.2 & 42.62 & 43.60 & 46.41 & 0.72 & 6.51 & 0.86 & 7.39 & 0.19 & 0.77 & 0.25 & 0.92 \\
\hline \multirow{3}{*}{ Christians } & Total & 60.55 & 55.36 & 57.06 & 51.44 & 37.07 & 39.08 & 40.29 & 41.97 & 2.2 & 5.11 & 2.44 & 6.17 & 0.19 & 0.45 & 0.21 & 0.42 \\
\hline & Rural & 60.45 & 55.24 & 57.09 & 51.41 & 37.1 & 39.16 & 40.21 & 42.00 & 2.26 & 5.15 & 2.49 & 6.18 & 0.19 & 0.45 & 0.21 & 0.41 \\
\hline & Urban & 62.32 & 57.66 & 56.50 & 52.07 & 36.47 & 37.57 & 41.64 & 41.34 & 1 & 4.35 & 1.49 & 6.04 & 0.21 & 0.42 & 0.37 & 0.55 \\
\hline \multirow{3}{*}{$\begin{array}{l}\text { Assam } \\
\text { (All } \\
\text { Religion) }\end{array}$} & Total & 59.7 & 50.97 & 55.34 & 46.17 & 38.66 & 41.75 & 42.88 & 45.68 & 1.48 & 6.75 & 1.59 & 7.57 & 0.16 & 0.53 & 0.19 & 0.58 \\
\hline & Rural & 60.4 & 51.52 & 56.04 & 46.95 & 37.89 & 41.22 & 42.14 & 45.07 & 1.55 & 6.71 & 1.65 & 7.40 & 0.61 & 0.55 & 0.17 & 0.58 \\
\hline & Urban & 55.19 & 47.07 & 51.08 & 41.39 & 43.62 & 45.53 & 47.35 & 49.38 & 1.01 & 6.98 & 1.27 & 8.65 & 0.18 & 0.42 & 0.3 & 0.58 \\
\hline
\end{tabular}

Source: Census of India 2001and C - 3 Marital Status By Religious Community And Sex -Census 2011

For instance, the sex ratio among the Hindus, consequently, leading to marginalisation of the Muslims and Christians residing in Assam society or a community. Hence, women being accounts for 958, 955,985 respectively. Such less in numbers due to imbalance in the gender gap would lead to large cohorts of numbers of male and female or low sex ratio 'surplus' males attending adulthood and can also be one of the reasons for increasing scarcity of female partners for marriage ability, demanding of early marriage of women.

Table 2: Proportion of Male and Female among Hindus, Muslims and Christians of Assam Marrying before Legal Age of Marriage, 2001-2011

\begin{tabular}{|c|c|c|c|c|c|}
\hline \multirow{2}{*}{ Religious groups } & \multirow{2}{*}{ Areas } & \multicolumn{2}{|c|}{2001} & \multicolumn{2}{|c|}{2011} \\
\hline & & Male & Female & Male & Female \\
\hline \multirow{3}{*}{ Hindus } & Total & 1.28 & 1.63 & 1.68 & 1.99 \\
\hline & Rural & 1.28 & 1.59 & 1.71 & 1.97 \\
\hline & Urban & 1.29 & 1.85 & 1.51 & 2.05 \\
\hline \multirow{3}{*}{ Muslims } & Total & 1.43 & 2.11 & 2.00 & 2.23 \\
\hline & Rural & 1.43 & 2.10 & 2.01 & 2.21 \\
\hline & Urban & 1.51 & 2.37 & 1.89 & 2.55 \\
\hline \multirow{3}{*}{ Christians } & Total & 1.24 & 1.34 & 1.73 & 1.96 \\
\hline & Rural & 1.25 & 1.33 & 1.74 & 1.95 \\
\hline & Urban & 1.18 & 1.56 & 1.66 & 2.28 \\
\hline \multirow{3}{*}{ Assam } & Total & 1.33 & 1.79 & 1.81 & 2.09 \\
\hline & Rural & 1.33 & 1.77 & 1.84 & 2.08 \\
\hline & Urban & 1.33 & 1.94 & 1.6 & 2.18 \\
\hline $\begin{array}{l}\text { Source: Census of In } \\
2011\end{array}$ & $C-3$ & ital s & 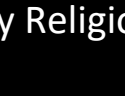 & Iun & Sex - \\
\hline
\end{tabular}


Table 3: Ever Married Persons*in Different Age Groups among Hindus, Muslims and Christians of Assam, 2011 (in percentage)

\begin{tabular}{|c|c|c|c|c|c|c|c|c|}
\hline \multirow{3}{*}{ Age at Marriage } & \multicolumn{8}{|c|}{ Ever Married Persons at Different Ages } \\
\hline & \multicolumn{2}{|c|}{ All Religions } & \multicolumn{2}{|c|}{ Hindus } & \multicolumn{2}{|c|}{ Muslims } & \multicolumn{2}{|c|}{ Christians } \\
\hline & Male & Female & Male & Female & Male & Female & Male & Female \\
\hline Less than 10 & 1.09 & 1.91 & 1.07 & 1.75 & 1.14 & 2.24 & 1.13 & 1.83 \\
\hline $10-11$ & 0.05 & 0.22 & 0.06 & 0.2 & 0.04 & 0.27 & 0.08 & 0.18 \\
\hline $12-13$ & 0.06 & 1.01 & 0.06 & 0.83 & 0.06 & 1.42 & 0.1 & 0.57 \\
\hline $14-15$ & 0.26 & 5.62 & 0.24 & 4.47 & 0.3 & 8.16 & 0.3 & 3.33 \\
\hline $16-17$ & 1.07 & 12.97 & 0.92 & 10.68 & 1.38 & 17.9 & 1.15 & 9.69 \\
\hline $18-19$ & 5.01 & 29.2 & 4.14 & 25.23 & 6.78 & 37.51 & 5.56 & 25.93 \\
\hline
\end{tabular}

Depending on the socio-cultural practices, economic condition and level of educational attainment, the age at marriage varies among the religious groups (Tables 3 and 4). The proportion of women getting married at younger age is an indication of advancement in the educational scenario. It is seen that the mind-sets of women and girls have changed in due course of time and they are more inclined towards economic independence rather than social custom of getting married at a specific age as prescribed by the society. Moreover, as per the Census of India (2011), the age gap of 14-19 years shows a high rate of marriage which is also not an encouraging figure. Early age at marriage is one of the reasons for more cases of separation. Moreover, Muslims women registering early age at marriage are exposed to high rate of child birth due to large reproductive span thereby, adding to the demographic number. The situation is almost similar in the rural and urban areas of the region (Table 5 ).

In addition, considerable percentage of females getting married at an early age, even before the prescribed age at marriage is the main factor that attributes to the high rate of maternal mortality (MMR of 300 per 100000 live births) for the state as against the National average of 167 per 100000 live births. ${ }^{11}$ Thus, early age of

11 Maternal Mortality Ratio (MMR) (per 100000 live births), NITI Aayog (National Institution for Transforming India), Government of India, retrieved 30 March 2018 from,http://niti.gov.in/content/maternal-mortality-ratiommr-100000-live-births\# marriage for females is not only impermissible for the socio-economic betterment of the women but also this has an adverse effect in the health condition among them. This consequently alters the age ratio and gender status of the society. Thus, although awareness and importance of proper age of marriage are been advised and several programmes in this regard have been taken up, yet the data interpreted regarding the age at marriage recommends for a better and stratified policies to persuade the society for girl child education, appropriate age of marriage and stable marital status, planned family size and economic selfcompetence among the population.

Thus, from the above made analysis it can be concluded that marital status is one of the important demographic determinants that governs the size of population within any region or social group. Marital status and age at marriage of women are important variables of demographic characteristics. Studying the various aspects of marital status among the Hindus, Muslims and Christians especially the figures related to women have given an exposition about the probability of natural growth of population as well as social manifestation prevailing in the society. The changing statistics for proportion of married, unmarried, widowed and separated/divorced females among the selected religious groups of Assam have a great impact on the social, cultural and demographic set up of the state. 
Table 4: Currently Married Persons among Hindus, Muslims and Christians in Assam in the Lower Age Groups, 2001-2011 (in percentage)

Area Total

Currently Married in Lower Age Groups

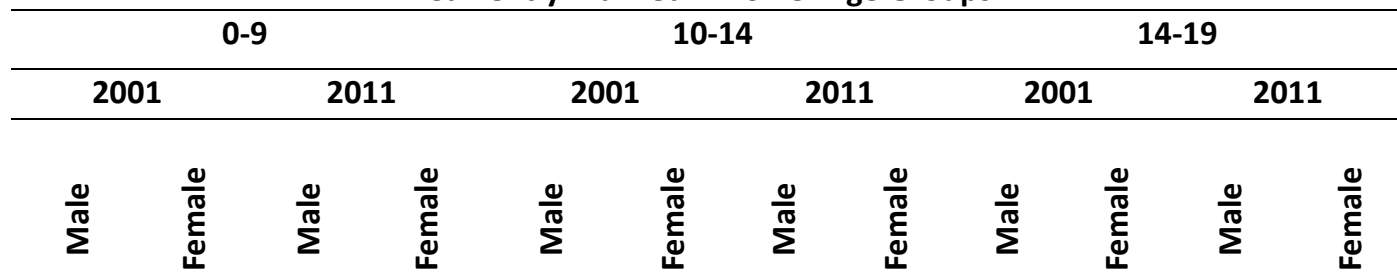

\begin{tabular}{|c|c|c|c|c|c|c|c|c|c|c|c|c|c|}
\hline \multirow[t]{4}{*}{ Total } & $\begin{array}{l}\text { All } \\
\text { Religion }\end{array}$ & 0.00 & 0.00 & 0.00 & 0.00 & 0.13 & 0.45 & 0.22 & 0.48 & 0.64 & 4.64 & 0.88 & 4.70 \\
\hline & Hindu & 0.00 & 0.00 & 0.00 & 0.00 & 0.13 & 0.41 & 0.19 & 0.42 & 0.57 & 3.68 & 0.71 & 3.48 \\
\hline & Muslim & 0.00 & 0.00 & 0.00 & 0.00 & 0.14 & 0.53 & 0.27 & 0.60 & 0.81 & 6.86 & 1.21 & 7.16 \\
\hline & Christian & 0.00 & 0.00 & 0.00 & 0.00 & 0.15 & 0.40 & 0.25 & 0.56 & 0.67 & 3.81 & 0.95 & 4.04 \\
\hline \multirow[t]{4}{*}{ Rural } & $\begin{array}{l}\text { All } \\
\text { Religion }\end{array}$ & 0.00 & 0.00 & 0.00 & 0.00 & 0.13 & 0.45 & 0.23 & 0.50 & 0.67 & 4.87 & 0.94 & 5.02 \\
\hline & Hindu & 0.00 & 0.00 & 0.00 & 0.00 & 0.13 & 0.41 & 0.20 & 0.43 & 0.60 & 3.87 & 0.77 & 3.75 \\
\hline & Muslim & 0.00 & 0.00 & 0.00 & 0.00 & 0.14 & 0.53 & 0.27 & 0.61 & 0.82 & 6.95 & 1.24 & 7.32 \\
\hline & Christian & 0.00 & 0.00 & 0.00 & 0.00 & 0.15 & 0.39 & 0.25 & 0.56 & 0.66 & 3.83 & 0.96 & 4.11 \\
\hline \multirow[t]{4}{*}{ Urban } & $\begin{array}{l}\text { All } \\
\text { Religion }\end{array}$ & 0.00 & 0.00 & 0.00 & 0.00 & 0.13 & 0.46 & 0.18 & 0.39 & 0.47 & 3.14 & 0.56 & 2.87 \\
\hline & Hindu & 0.00 & 0.00 & 0.00 & 0.00 & 0.13 & 0.44 & 0.17 & 0.35 & 0.44 & 2.75 & 0.49 & 2.36 \\
\hline & Muslim & 0.00 & 0.00 & 0.00 & 0.00 & 0.15 & 0.57 & 0.23 & 0.53 & 0.66 & 5.56 & 0.90 & 5.29 \\
\hline & Christian & 0.00 & 0.00 & 0.00 & 0.00 & 0.07 & 0.48 & 0.26 & 0.55 & 0.72 & 3.48 & 0.77 & 2.93 \\
\hline
\end{tabular}

Source: Census of India 2001and C - 3 marital statuses by Religious Community And Sex -Census 2011.

Table 5: Rural-Urban Differential of Ever Married Persons at Different Age Groups Among Hindus, Muslims and Christians of Assam, 2011

\begin{tabular}{|c|c|c|c|c|c|c|c|c|c|c|c|c|c|c|c|c|}
\hline \multirow{4}{*}{ Age at Marriage } & \multicolumn{16}{|c|}{ Ever Married Persons at Different Ages } \\
\hline & \multicolumn{4}{|c|}{ All Religion } & \multicolumn{4}{|c|}{ Hindu } & \multicolumn{4}{|c|}{ Muslim } & \multicolumn{4}{|c|}{ Christian } \\
\hline & \multicolumn{2}{|c|}{ Rural } & \multicolumn{2}{|c|}{ Urban } & \multicolumn{2}{|c|}{ Rural } & \multicolumn{2}{|c|}{ Urban } & \multicolumn{2}{|c|}{ Rural } & \multicolumn{2}{|c|}{ Urban } & \multicolumn{2}{|c|}{ Rural } & \multicolumn{2}{|c|}{ Urban } \\
\hline & $\frac{0}{\sum}$ & $\begin{array}{l}\frac{0}{\sigma} \\
\frac{\mathbb{U}}{U}\end{array}$ & $\frac{0}{\sum}$ & $\begin{array}{l}\frac{0}{\mathbb{T}} \\
\frac{\varepsilon}{0} \\
\amalg\end{array}$ & $\frac{0}{\frac{0}{\pi}}$ & 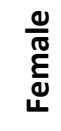 & $\frac{0}{\sum^{\pi}}$ & $\begin{array}{l}\frac{0}{N D} \\
\frac{E}{U} \\
\amalg\end{array}$ & $\frac{0}{\frac{0}{\pi}}$ & $\frac{0}{\frac{0}{\sigma}}$ & $\frac{0}{\sum^{\pi}}$ & $\begin{array}{l}\frac{0}{N D} \\
\frac{E}{U} \\
\amalg\end{array}$ & $\frac{0}{\frac{0}{10}}$ & $\begin{array}{l}\frac{0}{N D} \\
\frac{E}{U}\end{array}$ & $\frac{0}{\sum}$ & $\frac{\frac{0}{\pi}}{\frac{E}{0}}$ \\
\hline Less than 10 & 1.10 & 1.96 & 1.08 & 1.62 & 1.07 & 1.80 & 1.07 & 1.58 & 1.14 & 2.27 & 1.10 & 1.85 & 1.13 & 1.86 & 1.16 & 1.45 \\
\hline $10-11$ & 0.05 & 0.21 & 0.07 & 0.28 & 0.05 & 0.19 & 0.07 & 0.27 & 0.04 & 0.26 & 0.07 & 0.38 & 0.08 & 0.18 & 0.05 & 0.18 \\
\hline $12-13$ & 0.06 & 0.95 & 0.08 & 1.38 & 0.06 & 0.74 & 0.08 & 1.20 & 0.06 & 1.35 & 0.08 & 2.27 & 0.10 & 0.56 & 0.13 & 0.67 \\
\hline $14-15$ & 0.25 & 5.56 & 0.28 & 5.93 & 0.23 & 4.30 & 0.27 & 5.21 & 0.29 & 8.04 & 0.38 & 9.60 & 0.30 & 3.31 & 0.29 & 3.63 \\
\hline $16-17$ & 1.12 & 13.33 & 0.84 & 10.93 & 0.97 & 10.85 & 0.74 & 9.99 & 1.38 & 18.09 & 1.36 & 15.68 & 1.16 & 9.77 & 0.88 & 8.37 \\
\hline $18-19$ & 5.33 & 30.61 & 3.27 & 21.36 & 4.44 & 26.41 & 2.87 & 20.30 & 6.91 & 38.47 & 5.25 & 26.61 & 5.68 & 26.33 & 3.46 & 18.99 \\
\hline
\end{tabular}

Source: C-5 Ever Married And Currently Married Population By Age At Marriage, Duration Of Marriage And Religious Community Census 2011

Moreover, age at marriage also influence the population size and social scenario. Marital status and age at marriage of women is also important aspect that contributes towards the demographic dimension of any population group. It is quite astonishing to find that Hindus have more percentage of married women (47.15 per cent) compared to other two religious groups whereas the percentage of separated and divorced females are more among the Muslims ( 0.89 per cent). The more proportion of widow than the widower among 
these religious groups also advocates for longer life expectancy of females as compared to their male better halves. Moreover, the decreasing proportion of never married females during the period from 2001 to 2011 (50.97 per cent and 46.17 per cent respectively) among these religious groups stands for the fact that the acceptability and approach of the society towards unmarried women have changed to some extend over the years. However, the increasing percentage of divorced or separated females for the same duration among these religious groups is an indication of growing intolerance among the youths of the present societies. This also holds true in case of Hindu, Muslim and Christian women of the state. One of the important finding also is that the proportion of unmarried females are more among the Christians and Muslims (49.18 per cent and 51.44 per cent respectively) while it is lowest among the Hindus (44.16 per cent). Moreover, percentage of married women is more among the Hindus compared to the females of other two religions and still registering lowest marital fertility rate is an indication of adaptation of family planning measures among the Hindus. However, Muslims and Christians opt for having more number of children. The percentage of both male and female getting married at an age of below 18 years have risen up in 2011 (2.09 per cent) as compared to that in 2001 (1.79 per cent) in the state and among all the three religious groups. It is more in proportion among the Muslims girls (2.23 per cent) getting married below the legal age at marriage. Moreover, early age at marriage among the girls of Hindu, Muslim and Christians in the state is higher in the urban areas (2.05 per cent, 2.55 per cent, and 2.28 per cent respectively) compared to the rural areas (1.97 per cent, 2.21 per cent, and 1.95 per cent respectively). This has an adverse effect on the health condition of the female populace of the societies which in turn results in lowering of gender status. Moreover, early age at marriage for the females leads to broader fecundity period of women and thereby increasing the possibility of having more number of children.

\section{Conclusion}

This research set out to examine the changing trend of marital status of women of Assam belonging to three religious groups using Census of India data 2001 and 2011. Among the different religions of Assam, Hindu women have the highest married proportion followed by Christian while Muslim is the lowest in the same category. Depending on the socio-cultural practices, economic conditions and the level of educational attainment, the age at marriage varies among the religious groups. The proportion of woman being married at a younger age has been less, is an indication of advancement in the educational scenario and increasing self-competence among the female population of the region. Marital status and age at marriage also serve as vital indicators of demographic construct of any population group as it can give an exposition about the probability of fertility rate of women as well as social manifestation prevailing in the society. While this research is an addition to population studies of Assam, it calls for further research, perhaps, a detailed qualitative research to glean women's perspectives on marital status.

\section{References}

Agarwal, Bina (2016). Gender Challenges, Volume 2, Property, Family and the State, Oxford: Oxford University Press.

Census of India (2001). 1st Report on Religion Data, 13-42.

Census of India (2011). Religion Data C-1 Population by Religious Communities, C-15 Religious Communities by Age and Sex, C-3, Marital Status by Religious Communities and Sex, B-2 Working Population Classified by Age, Sex and Religion.

Bhattacharyya, Rituparna (2018). \#Metoo Movement: An Awareness Campaign, International Journal of Innovation, Creativity and Change, 3 (4), Special Edition: Teaching and Training in Cross Cultural Competencies, 1-12

Bhattacharyya, Rituparna (2016). Street Violence against Women in India: Mapping 
Prevention Strategies, Asian Social Work and Policy Review, 1-15.

doi:10.1111/aswp.12099

Bhattacharyya, Rituparna (2015).

Understanding the Spatialities of Sexual

Assault against Indian Women in India, Journal Gender, Place and Culture, 22(9), 1340-1356, doi:10.1080/0966369X.2014.969684.

Bhattacharyya, Rituparna (2013). Are we Empowered? Stories of Young Indian Working Women, Saarbrücken, Germany: Lap Lambert Academic Publishing.

Bhattacharyya, Rituparna (2009). Examining the Changing Status and Role of Middle Class Assamese Women: Lessons from the Lives of University Students, PhD Thesis, Department of Geography, University of Newcastle.

Bhattacharyya, Rituparna and Singh, Suman (2017). Exclusion (and seclusion): Geographies of Disowned Widows of India, GeoJournal, 82 (4), 1-18, DOI: $10.1007 / \mathrm{s} 10708-017-9800-0$

Das, Madhushree (2012).Tribal Women of Assam, EBH Publishers, Guwahati.

Das, Tulshi Kumar, Alam, Fakrul, Md., Bhattacharyya, Rituparna and Parvin, Amina(2015). Causes and Contexts of Domestic Violence: Tales of Help-Seeking Married Women in Sylhet, Bangladesh, Asian Social Work and Policy Review, 9(2), 163-176. doi:10.1111/aswp.12055.

Das, Tulshi Kumar, Bhattacharyya, Rituparna, Alam, Fakrul Md. and Parvin, Amina (2016).Domestic Violence in Sylhet, Bangladesh: Analysing the Experiences of Abused Women, Social Change, 46(1), 106123. doi: $10.1177 / 0049085715618561$

Goldman, Noreen, Korenman Sanders and Weinstein, Rachel (1995). Marital Status and Health among the Elderly, Social Science \& Medicine, 40 (12), 1717-1730, https://doi.org/10.1016/02779536(94)00281-W
Gove, Walter R (1972). The Relationship between Sex Roles, Marital Status, and Mental Illness, Social Forces, 51(1), 34-44

Havens, Elizabeth M. (1973). Women, Work and Wedlock: A Note on Female Marital Patterns in the United States, American Journal of Sociology, 78(4), 975-981

Hoffman Saul (1977). Marital Instability and the Economic Status of Women, Demography, 14 (1), 67-76, https://doi.org/10.2307/2060455

Kar, Bimal Kumar (2001). Population. In Bhagabati, A. K. et al. (eds.). Geography of Assam, Rajesh Publications, New Delhi, 11555.

Kar, Bimal Kumar (2002).Women Population of North East India: A Study in Gender Geography, Regency Publications, New Delhi, 175-190.

Millennium Development Goals Report (2015), retrieved 20 March 2018 from, http://www.un.org/millenniumgoals/2015 MDG_Report/pdf/MDG\%202015\%20rev\%20 (July\%201).pdf)

Nizami, Naheed and Ahmad, Rehana (JanuaryJuly 2005). Influence of Marital Status and Sex Role Orientation on Women Power, Journal of the Indian Academy of Applied Psychology, 31 (1-2), 29-36

Patidar, Hemant (2018). Women's Empowerment and Fertility Behaviour among the Tribals of Rajasthan, India, Space and Culture, India, 5(3), 129-139. https://doi.org/10.20896/saci.v5i3.285

Srivastava, Roli (2018, 6 March). India's Child Marriage Numbers Drop Sharply, Driving Down Global Rate, UNICEF, Reuters, retrieved 20 April 2018 from, https://www.reuters.com/article/us-indiagender-child-marriage/indias-childmarriage-numbers-drop-sharply-drivingdown-global-rate-unicef-idUSKBN1GI03F

Status of Woman and Family Planning (1975). Department of Economic and Social Affairs, New York: United Nations 
Sur, Esita (2014). Revisiting the Marginal Locations of Muslim Women on Various Sites in India, Space and Culture, India, 1(3), 43-52, https://doi.org/10.20896/saci.v1i3.44

Sur, Esita (2015). Politics of Locating Muslim Women in Islamic Discursive Tradition in India, Space and Culture, India, 3(1), 4-16, https://doi.org/10.20896/saci.v3i1.135

Sur, Esita (2018). Triple Talaq Bill in India: Muslim Women as Political Subjects or Victims? Space and Culture, India, 5(3), 5-12, https://doi.org/10.20896/saci.v5i3.299

Umberson Debra (1992). Gender, marital status and the social control of health behavior, Social Science \& Medicine, 34 (8), 907-917, https://doi.org/10.1016/02779536(92)90259-S

Vauquline, Polly (2015). Socialisation Process, Power Relations and Domestic Violence:
Marginal Voices of Assamese Women, Space and Culture, India, 3(2),54-71, https://doi.org/10.20896/saci.v3i2.155

Waldron, Ingrid, Hughes Elizabeth Mary, and Brooks, Tracey, L. (1996). Marriage Protection and Marriage SelectionProspective Evidence for Reciprocal Effects of Marital Status and Health, Social Science \& Medicine, 43 (1), 113-123, https://doi.org/10.1016/02779536(95)00347-9

Weingarten, H.R. (1985): Marital Status and Well-Being: A National Study Comparing First -Married, Currently Divorced, and Remarried Adults, Journal of Marriage and Family, 47(3), 653-662

Williams, Kristi and Umberson, Debra (2004). Marital Status, Marital Transitions, and Health: A Gendered Life Course Perspective, Journal Health Social Behavior, 45(1), 81-98 